\title{
Review of Biomass Energy utilization technology
}

\author{
Zhenglan $\mathrm{Li}^{\mathrm{a}}$, Zhenhua Xue $\mathrm{b}^{\text {* }}$ \\ College of Material Science and Art Design, Inner Mongolia \\ Agricultural University, Hohhot, 010018, China \\ a15847105305@163.com, bx_zhenhua@126.com
}

\begin{abstract}
Keywords: Biomass energy fuels energy conservation
\end{abstract}
Abstract. With the development of the society, oil and coal resources gradually reduce, as a sustainable, renewable energy, the development of biomass energy became the inevitable trend to save resources and protect the environment. At present, Biomass energy is rapidly developing in the paper-making, power, gas and liquid fuels, solid fuels and t metallurgical industry, contributing a lot to energy conservation and environmental protection, and is now one of the main research of new energy. This paper introduces the biomass energy utilization technologies and research status at home and abroad, in order to promote the development of biomass energy utilization technology in China.

\section{Introduction}

In recent years, China's traditional fossil energy reserves are dwindling, and the dependence on foreign energy is growing [1]. According to statistics, China's foreign oil dependency is $58.1 \%$, the situation is grim, the security of traditional fossil energy in China is faced with severe challenges. The burning of coal and oil will produce large amount of acid gases such as $\mathrm{SO}_{2}$, causing serious pollution of the atmosphere and environmental problems such as acid rain. In recent years, the air pollution caused by smog has become one of the main environmental problems in China [2].In addition, Acid rain pollution is becoming more and more serious in our country, especially in the coastal areas, these cities often suffer from acid rain pollution in recent years, seriously damaging the quality of people's living environment. Therefore, people are gradually seek new resources to reduce the environment pollution, improve the quality of people's lives.

Biomass energy resources are abundant, renewable and low pollution, attracting more and more attention of the human. It is reported that biomass energy has became the fourth energy after fossil fuels coal, oil and natural gas, accounting for $14 \%$ of the world's primary energy [3]. The utilization of modern biomass energy mostly use advanced conversion technology by means of thermal chemical, biological chemical to produce the high grade energy sources such as solid, liquid, gas to replace fossil fuels, provide power for production and life of the human and transportation fuel, heat, gas energy products [4].At present, Biomass as a renewable low-carbon energy, has great development potential. The development and utilization of biomass energy with modern high and new technology is of great significance in solving the double pressure of economic growth and environmental protection human faced, promoting the development of social economy and ecological environment.

\section{Utilization technology and application status of Biomass Energy}

There are many different kinds of biomass, as a result, biomass utilization technology is complicated. Biomass utilization is not limited to combustion method, but the modern efficient use. Today, biomass utilization means mainly divided into solid fuel molding technology, gas fuel molding technology and liquid molding technology.

Solid fuel molding technology. In solid fuel molding technology, wood sawdust, crops straw amorphous biomass are treated as raw material, they are squeezed into a certain shape by the curing equipment though a certain temperature and mechanical pressure, in order to concentrated the use of fuel, thus improving biomass original performance, increasing thermal efficiency. This kind of technology can not only be used in living cooking of urban and rural residents, but olso be used inr agricultural produce fuel, can be made into clean coal after further treat. Achieve the result of efficient, 
clean is a simple and feasible biomass energy production technology. Up to now, Biomass curing technology has developed many kinds of molding process and molding machinery [5].

The biomass solid molding technology have entered the industrialization stage in Europe and the United States and other countries, Widely applied in the Nordic region. The consumption of molding fuel in Denmark is about 700000 t, Thailand and other Asian countries also think highly of this technology, and have built a lot of biomass curing factories [6]. China has already formed more than 200 biomass fuel molding factory including leading enterprises such as Beijing green science and technology co., LTD., the annual output is more than 1 million $\mathrm{t}$.

\section{Gas fuel molding technology}

Biochemistry gasification technology. Biomass anaerobic fermentation to produce biogas. Biomass anaerobic fermentation is a process that place raw materials such as animal waste, straw, organic wastewater under anaerobic conditions to produce the mixed combustible gases such as $\mathrm{CH}_{4}$ and $\mathrm{CO}_{2}$ (gas) process through the metabolism of anaerobic bacteria. Now, biomass anaerobic fermentation technology has been more mature, preliminary realized commercialization, beginning to large-scale application development. Anaerobic fermentation can be divided into dry anaerobic fermentation and wet anaerobic fermentation. Compared with wet fermentation, dry fermentation technology has the advantage of saving water, saving management hours and the characteristic of high gas rate [7], becoming the main way of straw biomass resource utilization.

Currently, research on the mechanism of anaerobic fermentation biogas production, process optimization and preparation has been quite broad, but the anaerobic fermentation technology in our country is laggard compared with abroad, introducing massive actual application is not mature, Mainly because the system automation level is low, technology and equipment matching anaerobic fermentation is not sound, etc. China's ministry of agriculture organization with biogas technology as the core of ecological rich engineering and combining with energy and environment of large scale biogas project and quantity is very small; In such aspects as dry fermentation, biogas power generation is entering the exploratory study.

Thermochemistry gasification technology.Pyrolysis gasification. Biomass pyrolysis gasification technology mainly use straw, saw foam, under the condition of high temperature and hypoxia in the $g$ asification reactor to generate combustible gas containing carbon monoxide, hydrogen gas and low $\mathrm{m}$ olecular hydrocarbons. Biomass pyrolysis gasification technology usually use air, oxygen, water vapo $r$ as general gasification medium. Gasifier is main equipment of pyrolysis gasification. By adjusting th e way of gasification, the gasification medium and conditions, we can obtain different heating value of biomass fuel gas, so as to adjust the gas proportion of $\mathrm{CO}, \mathrm{CO}_{2}$, used in heat supply, gas supply, po wer generation and so on. Biomass gasification technology in China is mainly applied in small and me dium-sized gasification power generation and parts for industrial boiler heating.

There are about 350 biomass power plant in America, mainly using wood waste, municipal solid waste and other biomass materials waste. The total installed capacity of biomass power generation is more than 1.0 million $\mathrm{kW}$.At present, the biomass power industry has become the second renewable energy following the hydropower.

\section{Liquid molding technology}

Biochemistry liquid technology. Ethanol fermentation. Ethanol fermentation is a process that use biomass such as sugar, starch, wood fiber as raw materials to make biofuel ethanol by microbial fermentation. Fuel ethanol can be divided into two types of alternative fuels and fuel additives according to the proportion of ethanol. The fuel ethanol as additive have the effect of aerobic and antiknock, replace methyl tertiary butyl ether that has a carcinogenic effect [8]. Now the technology that use the sugar and starch as the raw material to produce fuel ethanol has been widely used in some countries, in 2011, Canada produce 170000 t ethanol with wood raw material. Belgium makes ethanol more than $32000 \mathrm{t}$ with sugar cane as raw material every year [9]. 
In 2000 , the production of 6 million $t$ corn ethanol, equivalent to $1 \%$ of the fuel consumption.It is estimated that if the United States agriculture and forestry wastes are used up, can replace the domestic $40 \%$ petrol [10]. Our country has rotten rice in Heilongjiang, Jilin, Henan, and anhui construction engineering to produce fuel ethanol, and has set up more than 10 cities across the country was carried out by adding $10 \%$ ethanol gasoline to demonstrate the application work [11].

Thermochemistry liquid technology. Biomass liquefaction system oil. Due to the structure of the solid biomass is loose, and energy density is low, direct burning process of biomass is illiquid and can't storage capacity. By thermalchemical conversion process, the maximum biomass can be converted to liquid fuel with high energy and high density, making the added value greatly improved and easy to store and transport. Different biomass raw materials produce different biomass liquefaction products, the main products include biological liquid fuel,biodiesel, ethanol and dimethyl ether, etc., they can replace petroleum energy products.

Biodiesel. Overall, the biodiesel production of major technical is chemical ester exchange method, mainly using liquid catalyst. Among them, the application of liquid alkali catalysis must strictly removing the free acid in raw oil and moisture, avoid catalyst deactivation and affect the efficiency of ester exchange; Application of liquid acid catalysis, although can make a small amount of water and free acid does not affect the yield, but methanol and byproduct glycerol into emulsion phase separation very hard, and acid corrosion of equipment. In addition, lquid alkali catalytic process of environmental friendliness is poor, and liquid alkali method are need to process after the separation process, is not conducive to efficient production. Due to biodiesel conversion processes of green demand, solid acid catalyst and continuous, dry cleaning and other advanced production technology is becoming the trend of the development of biodiesel technology, abroad is a lot of research work, and has obtained certain breakthrough [12]. In recent years, many breakthroughs were made in biodiesel technology in China.For example, the Chinese academy of agricultural sciences' oil developed by azeotropic distillation methyl esterification - biodiesel conversion technologies; Zuoyue energy company developed a new catalyst methyl and tubular continuous production device, implementation of three fatty acids in oils and fats gansu ester and fatty acid methyl ester reaction continuously, make more than $98 \%$ of the waste oil into biodiesel plants and animals, and to build the capacity of $120000 \mathrm{t}$ of biodiesel production base; Beijing university of chemical industry has developed special lipase esterification technology, enzyme activity has reached $1000 \mathrm{IU} / \mathrm{mL}$, exceeded the lipase on the international monopoly NOVOZYMES company in Denmark, and developed the world's first set of annual output of $200 \mathrm{t}$ enzymatic biodiesel pilot plant.

At present, in addition to the research on preparation of bio-oil using thermal chemical conversion,the preparation of biodiesel, ethanol and other oil fuel have a mature technology,and is going to carry out a further study on the transformation process by adjusting the process and the preparation conditions.

\section{Conclusion}

The proportion of biomass energy consumption in China has been relatively large, especially in the countryside, but the biomass utilization technology level is low.If we can make full use of biomass energy, not only can we reduce the pollution of the environment, but also can solve the energy crisis

facing future. Biomass energy products superior performance, and have broad application space, for the efficient use and sustainable development of energy is of great significance.

\section{Acknowledgements}

The project name: The research development and application of the baked charcoal burning Biomass(20111412) 


\section{References}

[1] $\mathrm{Wu}$ Chen. Yunfeng Li. Explore for the sustainable development of our country energy [J]. Energy technology economy, 2010, (5): 67.

[2] Yang Bai, Xiaoyuan Liu. "Smog" causes the deep legal thinking and countermeasures of [J]. Journal of China university of geosciences (Social science edition), 2013, (6) : 55.

[3] Forestry survey and design institute of Sichuan province. Wulong County forest resource survey [R]. 2003.

[4] Wulong County bureau of statistics. Wulong County statistics yearbook (2007) [M]. Chengdu: Sichuan people's publishing house, 2008.

[5] The rural KeJiaoChu of Jilin province. Straw energy utilization technology [J]. Journal of Jilin agriculture, 2008 (5) : 8-9.

[6] Shicai liu, Jian-chun Jiang. Biomass energy conversion technologies and applications ( II ) - fuel biomass compression molding production technology and equipment [J]. Journal of biomass, chemical engineering, 2007, 9 (4) : 59-63.

[7] Yue Qi. The best way to dry fermentation-straw resource utilization [J]. Agricultural engineering technology, new energy industry, 2010 (4) : 17-19.

[8] Yeying $\mathrm{Wu}$. Biomass research progress [J]. Journal of information science and technology, 2008 $(8): 8,10$.

[9] Qimei Chen, Yi-wu Weng. The use of biomass energy and development [C] / / "2006 national doctoral academic BBS BBS" -- - China biodiversity. Chengdu: [publisher unknown], 2006.

[10] GROSS R,LEACh M,BAUEN A.Progress in renewable energy [J].Environment International, 2003,29(1):105-122.

[11] Xiang hong Cao. Automotive fuel and chemical products bioengineering techniques [R]. Beijing: 2005 BBS biomass engineering, 2005.

[12] Guo-qiang Wang. the research institutes of office work efficiency management countermeasure thought [J]. Journal of anhui agricultural science bulletin, 2009, (16) : 222-223 . 